\title{
ASSESSMENT OF GOLD NANOPARTICLE EFFECT ON PROSTATE CANCER LNCaP CELLS
}

\author{
A.G. Reznikov ${ }^{1 *}$, O.A. Salivonyk ${ }^{1}$, A.G. Sotkis ${ }^{2,3}$, Y.M. Shuba ${ }^{2,3}$ \\ ${ }^{I}$ V.P. Komisarenko Institute of Endocrinology and Metabolism, \\ National Academy of Medical Sciences of Ukraine, Kyiv 01601, Ukraine \\ ${ }^{2}$ O.O. Bogomolets Institute of Physiology, Kyiv 01024, Ukraine \\ ${ }^{3}$ International Center of Molecular Physiology, NAS of Ukraine, Kyiv 01024, Ukraine
}

\begin{abstract}
In recent years gold nanoparticles (AuNPs) have received considerable attention for various biomedical applications including diagnostics and targeted drug delivery. However, more research is still needed to characterize such aspects of their use in clinical oncology as permeability, retention and functional effect on tumor cells. Aims: This study was designed to describe the effect of non-functionalized AuNPs on LNCaP prostate cancer cells growth. Material and Methods: LNCaP cells were cultured in RPMI-1640 medium containing AuNPs covered by polyvinylpyrrolidone of average size $26.4 \mathrm{~nm}(10.0 \mu \mathrm{g} / \mathrm{ml})$. Counts of cells were calculated and their morphology was examined. Results: AuNPs conglomerates have been visualized in cultured cells. After 4-day incubation in presence of AuNPs significant retardation of LNCaP cells growth was observed both in 5 $\alpha$-dihydrotestosterone stimulated and non-stimulated cultures. No morphological changes of live LNCaP cells were seen in any experiment. Conclusion: Given absence of morphological changes in live cells and dribble and relatively constant numbers of dead cells, it was concluded that inhibitory effect of AuNPs on LNCaP cells growth was caused by alterations of proliferation.
\end{abstract}

Key Words: prostate cancer, LNCaP, gold nanoparticles, 5 $\alpha$-dihydrotestosterone.

Prostate adenocarcinoma (prostate cancer $-\mathrm{PCa}$ ) is one of the most common cancer that affects $12-17 \%$ of male population in the developed countries [1, 2]. PCa case incidence and mortality increased during past decades. In the year of 2012, PCa in Ukraine was diagnosed as the second malignancy in human male population (after lung cancer) and the most common oncourological disease [3].

PCa represents a classical model of hormone-dependent malignancy. In the most cases, growth of $\mathrm{PCa}$ is promoted by testosterone and other androgens. For this reason, advanced PCa is quite successfully treated by surgical or pharmacological (androgen receptor antagonists, hypothalamic luteinizing hormone - releasing hormone analogues, estrogens and other drugs) androgen ablation. However, castration and hormonal therapy exert only palliative effect, and usually after remission the tumor relapses due to refractoriness to drugs. Some patients initially demonstrate refractoriness to castration or other modalities of systemic endocrine therapy. Possible mechanisms of hormone resistance include androgen receptor (AR) gene mutations and amplification, ligand-independent AR signaling, changed interplay between AR and growth factors, intratumoral conversion of adrenal androgens to testosterone, and so on. Alternative treatments are needed for aggressive localized PCa and hormone-refractory metastatic disease.

Modern nanotechnologies provide the new possibilities in biology and medicine $[4,5]$. In the recent

Submitted: February 24, 2015.

*Correspondence: E-mail: reznikov39@gmail.com

Abbreviations used: AR - androgen receptor; DHT -

5a-dihydrotestosterone; AuNPs - gold nanoparticles; PVP - polyvinylpyrrolidone; $\mathrm{PCa}$ - prostate cancer. decades, nanotechnology has brought new hopes in malignant tumors diagnosis and targeted therapy. Among various nanoparticles, the gold ones (AuNPs) have received considerable appreciation by investigators and clinicians due to their unique properties [6-8]. They have inert core, permeate through the cell membrane, can be functionalized easily, and demonstrate chemical stability and surface plasmon oscillation. Because of advanced technology of chemical synthesis, a large range of AuNPs with different size, shape and optical properties are available. Currently, the AuNPs are already applied or likely to be applied in the foreseeable future for bio-nano-analytics, diagnostic, photothermal therapy and targeted drug delivery [9-13]. In the meantime, however, clinical trials of AuNPs as antitumor agents are rather limited, and much more basic research is still needed to facilitate their transition to clinical oncology.

Earlier we observed suppressive effect of AuNPs on human PCa xenograft growth in mouse model [14]. Exploration of their effects on PCa cells in vitro could bring new information on the peculiarities of interaction between AuNPs and tumor cells. There was shown a cytotoxic influence of AuNPs on androgen-refractory PCa PC-3 cell line [15]. Cytotoxic activity of AuNPs conjugated with non-steroidal antiandrogens has been demonstrated in vitro toward hormone-insensitive PCa cell line [16]. Incorporation of AuNPs conjugated with glutamate carboxypeptidase inhibitor, prostatespecific membrane antigen, into LNCaP and PC-3 cells was observed [17], but their effects on the cells have not been studied. In this article, we represent the results of exploration of the effects of simple, non-functionalized AuNPs on androgen-sensitive $\mathrm{PCa}$ LNCaP cells growing freely or stimulated with 5a-dihydrotestosterone (DHT). 


\section{MATERIALS AND METHODS}

AuNPs. AuNPs were prepared using citric techniques of reduction of chloroauric acid [18], and kindly provided to us by the Research Institute for Nanotechnological Industry, Open International University of Human Development "Ukraine".

There was used ethanol dispersion of spherical AuNPs covered by polyvinylpyrrolidone (PVP) in order to prevent aggregation. The estimation of AuNPs parameters was carried out with laser correlation spectroscopy (Zetasizer-3, Malvern Instruments Ltd, UK).

Cells and experimental protocol. Human $\mathrm{PCa}$ cell line LNCaP was provided by R.E. Kavetsky Institute of Experimental Pathology, Oncology and Radiobiology, National Academy of Sciences of Ukraine, Kyiv. Three series of experiments with similar design were carried out. Cells were cultured on $24 \times 24 \mathrm{~mm}$ square glass cover slips placed in Petri dishes filled with culture medium of the following composition: RPMI1640 medium (Sigma), 10\% fetal bovine serum (Sigma), $50.000 \mathrm{lU} / \mathrm{l}$ penicillin and $50 \mathrm{mg} / \mathrm{l}$ streptomycin. Cell cultures were maintained in the thermostat at $37^{\circ} \mathrm{C}$ in a $95 \%$ air $-5 \% \mathrm{CO}_{2}$ humidified atmosphere. Culture medium was changed daily.

After cells' density reached $50-60 \%$ of cover slip's surface, the cultures were separated onto 5 groups each consisting of 3-5 cover slips. The culture medium in the first group (control) contained ethanol, and the second one (PVP group) contained PVP-ethanol solution just to make sure it doesn't affect cells. The third group (AuNPs group) was exposed to AuNPs $(10 \mu \mathrm{g} / \mathrm{ml})$ alone, the fourth group (DHT group) contained DHT $\left(10^{-4} \mathrm{M}\right)$ alone, and the fifth group (AuNPs + DHT group) was supplemented with AuNPs $(10 \mu \mathrm{g} / \mathrm{ml})$ plus DHT $\left(10^{-4} \mathrm{M}\right)$. Ethanol concentration in culture medium of all experimental and control groups did not exceed $1 \%$. After 4-days of culturing with daily replacement of respective medium, cells from each group were detached from cover slips using $0.25 \%$ trypsin-EDTA in $0.5 \mathrm{ml}$ medium, suspended in additional $0.5 \mathrm{ml}$ medium and centrifuged at $3200 \mathrm{rpm}$. The cells were resuspended in $1.0 \mathrm{ml} \mathrm{me-}$ dium, stained with Trypan Blue in order to discriminate live and dead cells, and the numbers of live and dead cells were calculated in Goryaev chamber.

Morphological studies. Part of cover slips was used for morphological studies. The cells were fixed in $4 \%$ paraformaldehide, then stained with Ferrum hematoxylin and underwent examination using the microscope Leika DME (Leika Microsystems, Germany).

Data analysis and statistics. Each experiment was repeated 4-6 times. Accretion percentage of cell counts in relation to initial seeding was calculated, and results were averaged and expressed as mean \pm s.e.m. (standard error of the mean). The results were compared with those of appropriate controls. Student's $t$-test was used for statistical analysis, with $p<0.05$ considered significant.

\section{RESULTS AND DISCUSSION}

AuNPs size measurements. It has been estimated that the colloidal solution contained nanoparticles with sizes ranging from 15.3 to $30.9 \mathrm{~nm}$ (90\% of total number) and the prevalence of $21.8 \mathrm{~nm}$ one ( $42 \%$ of total number) (Fig. 1). The average size of nanoparticles was estimated as $26.4 \mathrm{~nm}$.

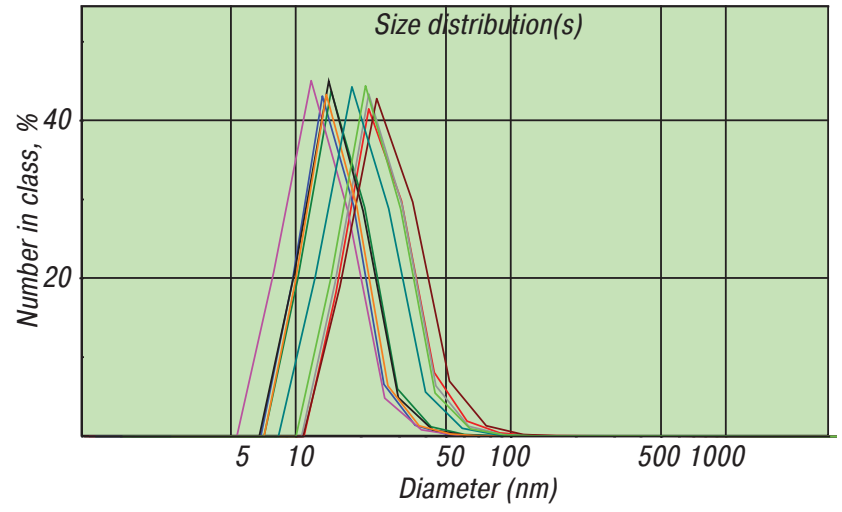

Fig. 1. AuNPs size (diameter) and number distribution by laser correlation spectroscopy

LNCaP cells growth. During 4-day-growth period, a total count of control LNCaP cells (i.e., cultured in the presence of ethanol and/or PVP) increased 7-21-fold. The relative numbers of dead cells against initial seeding increased only 2 -fold, and was similar in all control and experimental groups. Given a total numbers of cultivated cells and numbers of live and dead cells in the end of the experiments, PVP in appropriate amounts did not affect the culture growth versus the vehicle control $(p>0.05)$ (Fig. 2).

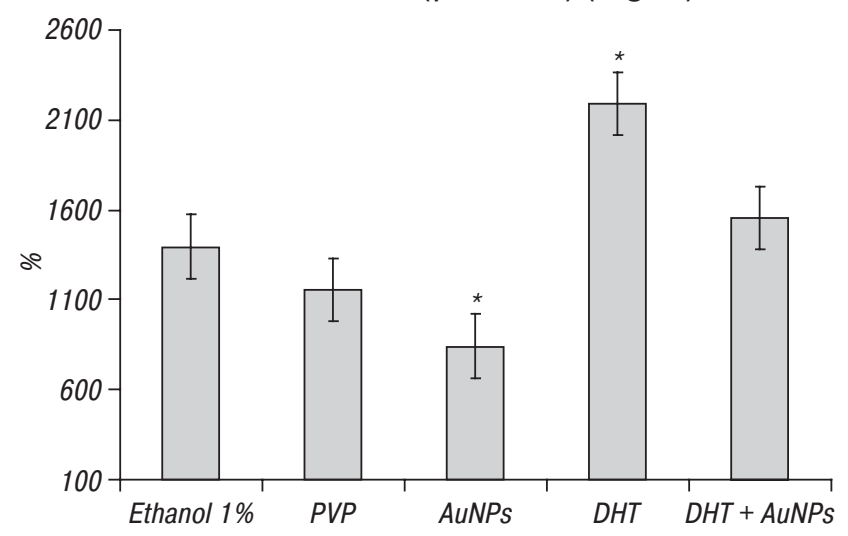

Fig. 2. Effect of AuNPs on percentage of total counts of LNCaP cells after 4-day cultivation in RPMI 1640 medium in relation to initial seeding $(\mathrm{M} \pm \mathrm{m})$. Footnotes: Each bar represents an average data from 3 experiments. ${ }^{*} p<0.05$ in comparison with ethanol control

Our preliminary in vitro experiments with various AuNPs concentrations of $0.1 ; 1.0$ and $10.0 \mu \mathrm{g} / \mathrm{ml}$ had shown that only $10.0 \mu \mathrm{g} / \mathrm{ml}$ of AuNPs was effective in affecting $\mathrm{LNCaP}$ cells growth. In this study, after 4-day incubation of $L N C a P$ cells in presence of AuNPs $(10.0 \mu \mathrm{g} / \mathrm{ml})$ we observed significant suppression of cells' growth. AuNPs decreased the total cells count on average by $40 \%$ and live cells count by $43 \%$ compared to the control, and both decreases were statistically significant $(p<0.02)$.

Supplementing culture medium with DHT stimulated LNCaP cells growth by increasing total cells count 
on average by $57 \%$ and live cells count by $61 \%$ compared to the control. Addition of AuNPs in the presence of DHT dramatically reduced stimulatory effect of DHT on LNCaP cells growth by $80 \%$ and $77 \%$ when counted by the accretion of total and live cells, respectively, and brought total cell counts to control level ( $p>0.05$ ).

Cell morphology. Dark violet increments, supposedly aggregates of nanoparticles, were clearly seen in cells cultivated with AuNPs. No morphological changes of live LNCaP cells were seen in any experiment (Fig. 3).
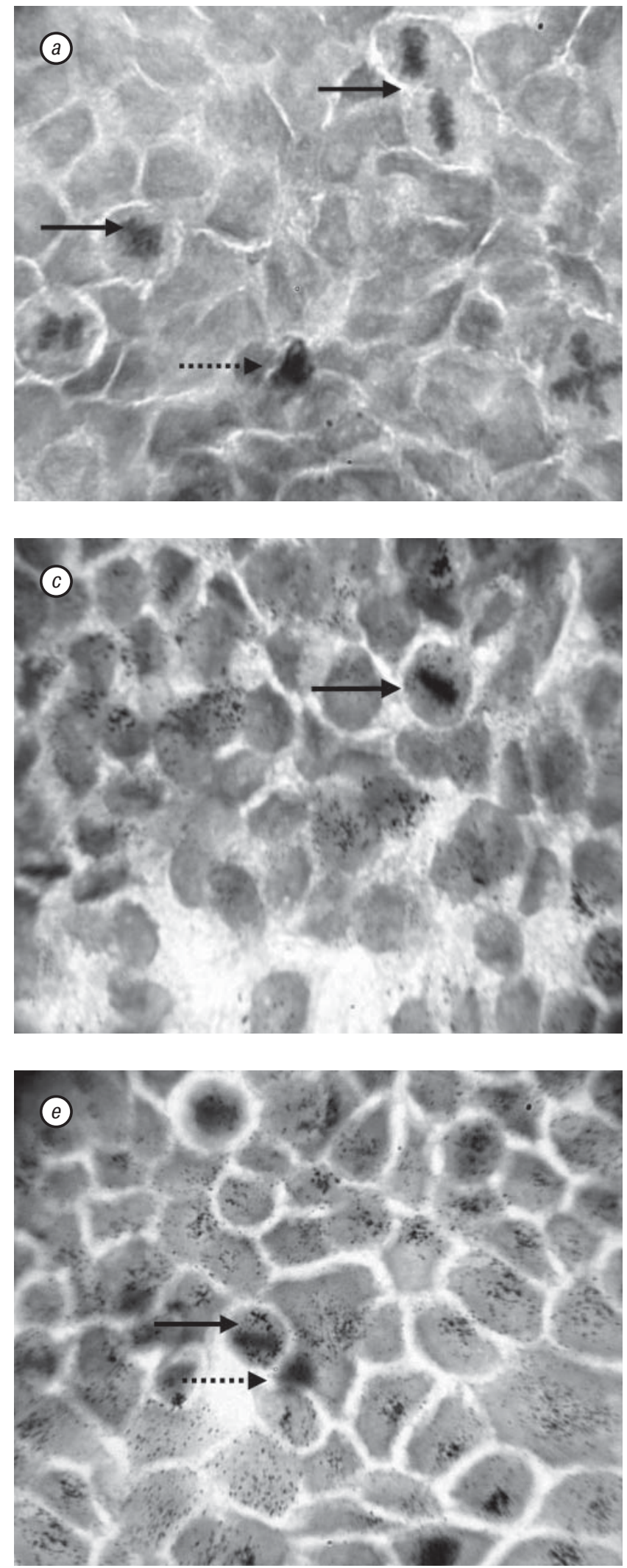

In summary, it must be emphasized that we used androgen-sensitive LNCaP cell line derived from the human PCa lymph node metastasis to study the effects of non-functionalized AuNPs on cells' growth.

There is some discrepancy in published works concerning cytotoxicity of AuNPs toward eukaryotic cells. Cytotoxicity has been reported by a few authors [19, 20], meanwhile others did not observe it [21]. Cytotoxity of AuNPs both in vitro and in vivo strongly depends on particles' size, shape, dose, surface composition
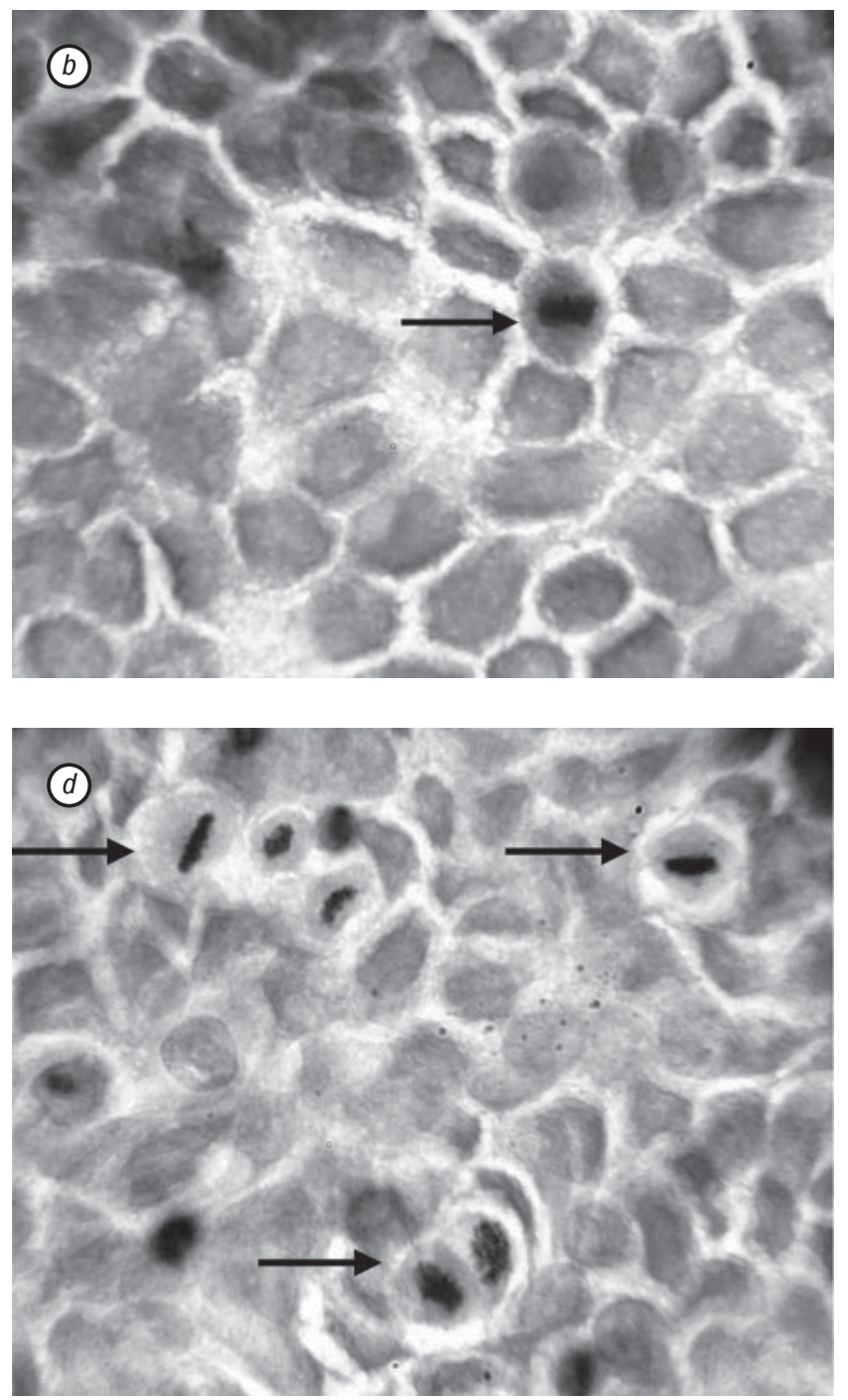

Fig. 3. Appearance of DHT stimulated and non-stimulated LNCaP cell cultures after 4 days growing with AuNPs $(a-96 \%$ ethanol; $b-$ PVP ethanol solution; $c-$ AuNPs $(10 \mu \mathrm{g} / \mathrm{ml})$, visualization of the nanoparticle aggregates; $d-\mathrm{DHT}(10-4 \mathrm{M})$; increased mitotic activity; $e-$ AuNPs $(10 \mu \mathrm{g} / \mathrm{ml})$ and DHT (10-4 M), visualization of the nanoparticle aggregates). Ferrum hematoxylin, $\times 300$. Entire arrows indicate mitosis, dot arrows indicate apoptosis 
and other features [15, 22-24]. Similarly to other metallic nanoparticles, AuNPs interact with cellular membrane, mitochondria, nucleus, resulting in damaging DNA and organelles, oxidative stress, apoptosis.

In this study, we explored relatively homogenous population of spherical AuNPs with average size of about $26 \mathrm{~nm}$. By being added to the culture medium at concentration $10.0 \mu \mathrm{g} / \mathrm{ml}$, these AuNPs inhibited non-stimulated LNCaP cell line growth significantly. The ratios of dead cells in the control and AuNPs-treated cultures relative to the initially seeded cells were minor and remained quite constant, whereas the relative numbers of live cells in the presence of AuNPs decreased dramatically. Suppression of cell growth by AuNPs in DHT stimulated culture was quite noticeable. Taken into consideration that $\mathrm{DHT}$ binds to nuclear AR, which interacts with specific regions of DNA followed by expression of growth factors and stimulation of mitosis, it can be assumed that AuNPs interfere with androgen and/or growth factor signaling in the affected cancerous cells. Morphology of live cells did not change, and numbers of visualized apoptotic cells were similar in control and experimental groups. From these observations, we have concluded, that AuNPs suppressed cell proliferation rather than caused apoptosis or necrosis.

AuNPs conglomerates have been visualized in cultured cells, which is in line with reported data on the ability of nanoparticles with $30 \mathrm{~nm}$ diameter or less to be endocytosed by cells $[15,20,25,26]$. It was shown in human histiocyte-rich lymphoma U937 cell line that 20-30 nm AuNPs have a greater cell accumulation than that of nanoparticles of other size with prevalent localization in the lysosomes [11, 20]. 3-5 nm AuNPs penetrate nucleus easily. AuNPs capacity to damage DNA deserves special attention in terms of their safety. It was shown that even 10-20 nm AuNPs can damage DNA structure in $\mathrm{CHO}-\mathrm{K} 1$ cell line, meanwhile $30 \mathrm{~nm}$ and $45 \mathrm{~nm}$ AuNPs were safe [27]. Genotoxity might be a cause of suppressive influence of AuNPs on LNCaP cell growth in our experiments.

One possible mechanism of AuNPs induced inhibition of $\mathrm{LNCaP}$ cell growth is modulation of the cell membrane enzyme activity. Though gold per se is known to be inert metal, AuNPs possess high catalytic properties [5]. For instance, it had been reported their ability to modulate in vitro the U937 tumor cell membrane $\mathrm{Na}^{+}$, $\mathrm{K}^{+}$-ATPase activity [20]. Since $\mathrm{Na}^{+}, \mathrm{K}^{+}$-ATPase activity is required for adequate regulation of cell volume, which undergoes significant disturbances during cellcycle progression, one might suggest that impaired cell volume regulation may in part be responsible for the anti-proliferative action of AuNPs. However, biochemical mechanisms underlying effect of AuNPs on cancerous cells are still poorly investigated and understood.

There is a hope that in the future AuNPs could earn a place in the treatment of $\mathrm{PCa}$, however, much work for this is to be addressed.

\section{ACKNOWLEDGEMENTS}

The authors are grateful to Dr. A.V. Usatenko, Director of the Research Institute of Nanotechnological Industry, Open International University of Human Development "Ukraine", for donating AuNPs for the study. We would like to thank Dr. O.Yu. Chunikhin (O.V. Palladin Institute of Biochemistry, National Academy of Sciences of Ukraine) for his kind help on carrying out laser spectroscopy of the AuNPs preparation.

\section{REFERENCES}

1. Ferlay J, Shin HR, Bray F, et al. Estimates of worldwide burden of cancer in 2008: GLOBOCAN 2008. Int J Cancer 2010; 127: 2893-917.

2. Siegel R, Ward E, Brawley O, Jemal A. Cancer statistics, 2011: the impact of eliminating socioeconomic and racial disparities on premature cancer deaths. CA Cancer J Clin 2011; 61: 212-36.

3. Grigorenko VM, Saydakova NO, Danilets RO, et al. Features of the demographics of the population of Ukraine in terms of the prevalence of prostate cancer. Sci J Health Ministery 2014; 5: 85-92 (in Ukrainian).

4. Nanomaterials and supramolecular structures: physics, chemistry, and applications. AP Shpak, PP Gorbik, eds. Springer, 2009. $420 \mathrm{p}$.

5. Chekman IS. Nanoparticles: properties and perspectives of application. Ukr Biochem J 2009; 81: 122-9 (in Ukrainian).

6. Levy R, Shaheen U, Cesbron Y, et al. Gold nanoparticles delivery in mammalian live cells: a critical review. Nano Rev 2010; 1: 10.3402 .

7. Daniel MC, Astruc D. Gold nanoparticles: assembly, supramolecular chemistry, quantum-size-related properties, and applications toward biology, catalysis, and nanotechnology. Chem Rev 2004; 104: 293-346.

8. Eustis S, El-Sayed MA. Why gold nanoparticles are more precious than pretty gold: Noble metal surface plasmon resonance and its enhancement of the radiative and nonradiative properties of nanocrystals of different shapes. Chem Soc Rev 2006; 35: 209-17.

9. Huang X, El-Sayed IH, Qian W, et al. Cancer cell imaging and photothermal therapy in the near-infrared region by using gold nanorods. J Am Chem Soc 2006; 128: 2115-20.

10. Boisselier E, Astruc D. Gold nanoparticles in nanomedicine: preparations, imaging, diagnostics, therapies and toxicity. Chem Soc Rev 2009; 38: 1759-82.

11. Chithrani BD, Stewart J, Allen C, et al. Intracellular uptake, transport, and processing of nanostructures in cancer cells. Nanomedicine 2009; 5: 118-27.

12. Wiwanitkit V, Sereemaspun A, Rojanathanes R. Gold nanoparticle as an alternative tool for urine microalbumin test: the first world report. Renal Failure 2007; 29: 1047-8.

13. Chanda N, Kattumuri V, Shukla R, et al. Bombesin functionalized gold nanoparticles show in vitro and in vivo cancer receptor specificity. Proc Natl Acad Sci USA 2010; 107: 8760-5.

14. Reznikov AG, Polyakova LI, Usatenko AV, et al. Gold nanoparticles exhibit antitumor activity in heterotransplants of androgen dependent human prostate cancer. Pharmacol Drug Toxicol 2013; 34: 58-62 (in Ukrainian).

15. Rieznichenko LS, Shpyleva SI, Gruzina TG, et al. Cancer cells - gold nanoparticles contact interaction determined by their size and concentration. Rep Natl Acad Sci Ukr 2010; 2: 170-4 (in Ukrainian).

16. Dreaden EC, Gryder BE, Austin LA, et al. Antiandrogen gold nanoparticles dual-target and overcome treat- 
ment resistance in hormone-insensitive prostate cancer cells. Bioconjug Chem 2012; 23: 1507-12.

17. Kasten BB, Liu T, Nedrow-Byers JR, et al. Targeting prostate cancer cells with PSMA inhibitor-guided gold nanoparticles. Bioorg Med Chem Lett 2013; 23: 565-8.

18. Usatenko OV, Shcherbakov OB, Kushchevska NA, et al. Composition containing gold nanoparticles and method of its preparation. Bulletin № 15, 2009. Patent of Ukraine № 87744 (in Ukrainian).

19. Goodman CM, McCusker CD, Yilmaz T, et al. Toxicity of gold nanoparticles functionalized with cationic and anionic side chains. Bioconjug Chem 2004; 15: 897-900.

20. Rieznichenko LS, Dybkova SM, Gruzina TG, et al. Gold nanoparticles synthesis and biological activity estimation in vitro and in vivo. Exp Oncol 2012; 34: 25-8.

21. Connor EE, Mwamuka J, Gole A, et al. Gold nanoparticles are taken up by human cells but do not cause acute cytotoxicity. Small 2005; 1: 325-7.
22. Alkilany AM, Murphy CJ. Toxicity and cellular uptake of gold nanoparticles: what we have learned so far? J Nanopart Res 2010; 12: 2313-33.

23. Chueh PJ, Liang RY, Lee YH, et al. Differential cytotoxic effects of gold nanoparticles in different mammalian cell lines. J Hazard Mater 2014; 264: 303-12.

24. Khlebtsov N, Dykman L. Biodistribution and toxicity of engineered gold nanoparticles: a review of in vitro and in vivo studies. Chem Soc Rev 2011; 40: 1647-71.

25. Conner SD, Schmid SL. Regulated portals of entry into the cell. Nature 2003; 422: 37-44.

26. Gao HJ, Shi WD, Freund LB. Mechanics of receptor-mediated endocytosis. Proc Natl Acad Sci USA 2005; 102: 9469-74.

27. Dybkova SM, Rieznichenko LS, Gruzina TG, et al. Gold nanoparticles analysis by the method of alkaline gelelectrophoresis of isolated eukaryotic cells. Rep Natl Acad Sci Ukr 2010; 3: 166-70 (in Ukrainian). 